\title{
Research on the channels for creation and development of high-quality "green manufacturing" brands - a case study of Xiamen
}

\author{
Zhang Xiujuan $^{1, \mathrm{a}^{*}}$, Zhao Pingyuan ${ }^{1, \mathrm{~b}}$ \\ ${ }^{1}$ Art Management Division of Fine Arts Department, College of Arts \& Design of Jimei University, Xiamen, Fujian, China
}

\begin{abstract}
: as the manufacturing industry gains momentum around the world, the conflicts between its rapid development and the accompanying consumption of materials, discharge of wastes and ecological impacts spiral. Governments around the world have explored measures and made achievements in alleviating the dual pressures from economic growth and environmental degradation. As for the overall trend of the manufacturing industry, creating and developing "green manufacturing" brands is the only way for the manufacturing industry to achieve further development. It is of great significance to design guidelines for green manufacturing from the angle of branding, the green notion provides more profundity and the soul to brands, ensuring sustainable development of brands. The development of green brands in Xiamen has adopted a global vision and related to the local realities, which would provide lessons for high-quality development of green manufacturing brands in other places.
\end{abstract}

\section{Introduction}

With the boom of the manufacturing industry across the globe, the conflicts between its rapid development and the accompanying consumption of materials, discharge of wastes and ecological problems grow in intensity. To address the dual pressures from economic growth and environmental protection, the U.S., EU, Japan, South Korea and other countries and regions have proposed the solution of green development. For instance, the "re-industrialization" initiative in the U.S. aimed to lead a new wave of technological innovation for efficient use of resources with intelligence, information, and digitalization as the orientation. In February 2003, the U.K. government for the first time put forward the notion "low-carbon economy", and in "Our energy future creating a low carbon economy", the U.K. government pointed out that low carbon economy is a new economic development model featured by low energy consumption, low emissions and low pollution. Similar endeavors include the "New Industrial France" initiated by the French government, the "Japan is Back" initiative in Japan, and the "Industry 4.0" proposed by Germany. China has also followed the trend. In November 2014, President Xi Jinping announced to the world the goal of cutting green-house gas emissions, promising to retain the emission of $\mathrm{CO}_{2}$ after it reaches the maximum in 2030 and then shift the country into a low-carbon economy. As pointed out in its report of the $19^{\text {th }}$ People's Congress, "improving ecological conservation is a thousand-year mission that is concerned with China's sustainable development. We need to stick to the notion that 'green mountains and lush water is invaluable treasure', to practice a green lifestyle and development mode". In the government work report made during the two sessions in 2021, the ideas of "carbon emission peak" and "carbon neutral" were proposed, and it was pointed out that we need to formulate an action plan for carbon emissions before 2030 to optimize the industry structure, develop clean-energy industries to reach harmony between economic growth, resource development and environmental protection. In this context, the importance of green manufacturing is again accentuated. In 2020, Xiamen achieved a GDP of 638.402 billion yuan, and the value of industries there increased by 189.208 billion yuan, a year-on-year increase of $5.4 \%$. Meanwhile, giving priority to ecological wellbeing and green development, Xiamen has built high-standard national ecological conservation demonstration zones and aimed to create a "blooming city in gardens". The city has won a series of honorary titles including national ecological city, national garden city, national ecological and garden city, international garden city, a livable city granted by the UN, and the national model city for environmental protection, just to name a few. These honors are manifestations of the great achievements that Xiamen has made in building an ecologically-friendly garden city over these four decades since it was made an economic special zone. It is worth exploring how Xiamen managed to achieve economic growth while maintaining natural beauty. 


\section{Related theories of green manufacturing}

\subsection{Green manufacturing theory}

Green manufacturing is a modern model of manufacturing that fully considers environmental impacts and resource consumption. The specific contents of this notion include the theories and technologies of green manufacturing. With the theoretical framework, key technologies, environmental management standards and laws as the major research content, a system of the green manufacturing discipline can be established based on analysis of the following aspects: the features of resources and conditions of resource consumption in the manufacturing system, the multi-life-cycle engineering, the green manufacturing decision-making model, the green manufacturing integrated characteristics, the integrated green manufacturing system, the green design technologies, green manufacturing-oriented techniques and clean production technologies, materials selection techniques, green packaging technologies, waste recycling and re-production technologies, as well as environmental management standards and regulations specific to green manufacturing.

\subsection{Innovation models of green manufacturing}

The theory of green manufacturing is proposed based on industrial symbiosis and resource recycling. In these years, developed countries in the west have probed into the new models of green manufacturing and concluded the following representative models: industrial symbiosis model, eco-plant model and extended producer responsibility (EPR) industry system model. The major feature of the industrial symbiosis model is that a top ecological industry chain is designed as the leading core of the model, and the sub-systems involve three elements including the society, economy and environment; it is a modern industry development model featured by resource conservation, environmental protection and a high comprehensive resource utilization rate. Denmark has already built the world's first industrial symbiosis the Kalundborg Symbiosis. In the eco-plant model, eco-plants that realize self-sufficient supply of energy by utilizing the principles of symbiosis of species, the cycling, conversion and regeneration of matters, the system engineering optimization methods and relying on new energy and cutting-edge energy recycling technologies. This model has refined design of the cycling system of resources to maximize utilization of resources. The EPR ecological model sets constraints to the producers. In 1988, the Swedish researcher Thomas put forward the idea of EPR in a report it delivered to the Swedish Environmental Protection Agency, in which he argues that EPR is an environmental protection strategy aimed to reduce the impacts of products on the environment. EPR takes effect by making the producers responsible for the whole life cycle of the products, including the recycling and final disposal of the products. The chairman of the well-known green manufacturer
Desay has announced that as a top brand in the world, Desay should undertake the responsibility of promoting environmental protection, and integrate low-carbon development into its long-term development plans while providing high-quality technologies and products to the consumers and market, thereby taking up the mission of the time. The innovation and practice of industrial models will become the driving force of green manufacturing.

\subsection{China's green manufacturing strategies}

The Chinese government sets great store by green manufacturing. In February 2006, the State Council released "Outline for medium- and long-term development of science and technology (2006 - 2020), in which the green manufacturing was specified as one of the three orientations of development of manufacturing technologies. In July 2011, the Ministry of Science and Technology released "Science and Technology Development in the $12^{\text {th }}$ Five-Year Plan", which clearly stated the need to "give priority to development of advanced and green manufacturing technologies and products, make breakthroughs in design of green products, environmentally-friendly materials, energy-conservation techniques and green recycling techniques". In May 2015, the State Council released "Made in China 2025", which pointed out that we should "fully promote green manufacturing", implement "green manufacturing projects", invest more into R\&D of energy conservation and environmental protection techniques, accelerate upgrading of the green manufacturing industry, promote low-carbon, recyclable and integrated industries, and improve the resource utilization rate of the manufacturing industry; it also plotted the development path to strengthen full-life-cycle green management, and develop a highly-efficient, clean, low-carbon and recyclable green manufacturing system.

\subsection{Importance of developing green manufacturing brands}

Developing green manufacturing brands is an important guarantee for high-quality development and green innovation. Overall, the purpose of high-quality development is to "meet the needs of people for a better life", and the basic concepts are the "five development theories"; it covers not only the products and services at the microscopic level, but also the structure and efficiency at the macroscopic level; and the fundamental path is green development. The indicator system of high-quality development should be established based on the production efficiency, technological innovation and green ecology. Green development is an inevitable path to take towards high-quality development, and only by realizing green development can we reach the goal of resource conservation and environmental protection. 


\section{A case study for development green manufacturing brands in Xiamen}

\subsection{Xiamen King Long Motor Group}

Xiamen King Long Group, founded in 1988, is a listed company specializing in manufacturing and sales of large, medium- and small-sized cars. With its markets covering Xiamen, Suzhou, Shaoxing, Xi'an and Shanghai, the company has built a car industry cluster that combines manufacturing of parts and whole vehicles. The whole vehicles produced by King Long have a length ranging from $4.3 \mathrm{~m}$ to 18 , and its cars have been sold in 160 countries and regions across the world. Their products have been widely used in passenger transportation, tourism, bus systems, group travels and special-purpose tasks, with broad recognition from the customers.

World Brand Lab has, in 2020, released the ranking of the 500 Most Valued Brands in China, in which King Long ranked the $115^{\text {th }}$ with a value of 52.036 billion yuan, an increase of $14.6 \%$ compared with in 2019 . When the manufacturing industry takes the full force of the Covid-19 pandemic, King Long has achieved a rise in its value, which manifests the power of its brand.

More excitingly, on $27^{\text {th }}$ May 2020, 200 high-end urban busses developed by King Long left Xiamen for Cyprus. As the first automobile brand that entered the market of Europe, King Long marked the start of Chinese automobile brands into the European market. The 200 exported high-end buses of King Long are the U12 and B12 models. The design of these models relied on principles of ergonomics and ecological conservation, and except the automatic spraying system, the models have thorough upgrading of active-passive safety, comfort, energy conservation and customized design, which not only improved the quality of the vehicle models, but extended the value of the brand. "the European market is now relying more and more on new energies, in the future, King Long needs to, relying on its strength in electrification, intelligent operation and complete industrial network, output achievements in intelligent manufacturing, expand its impact in the Europe, and shape the new image of Chinese cars" [1], as pointed out by Zhao Yutong, the regional general manager of King Long in Europe. On August 26 ${ }^{\text {th }}, 2020$, King Long held a cloud launch event with the theme "creating a nice community for travel", in which the new branding strategy, the solution of intelligent transportation, and the new customer service brand were identified. This launch drew a large audience and received applauses from the market, marking a milestone in the history of King Long Motor Group.

King Long Motor, with over thirty years of experience in car manufacturing, is well aware that technology is the driving force of human development, and hence keeps pursuing independent innovation and moving towards the cutting edge of technological innovation of cars. Meanwhile, King Long is oriented to public welfare and social needs in its pursuit of technological progress, and with safety, comfort and ecological protection as the benchmark, it aims to expand its business from commuting services to hiking services, from business trips to sightseeing, from regular delivery services to cold-chain delivery services, or even more convenient, healthy and user-friendly services for health care and blood-sampling for pregnancy tests. As the motto of King Long states: "honesty begets trust". With the goal of creating a nice community for travelling and striving for a better life for people and a community of shared future among all members of the society, King Long has been increasing the value of its brand and increasing its brand impact.

One lesson in King Long's persistence of creating a green manufacturing brand is that it takes independent innovation of technologies as the core and has made considerable achievements in research and development of new products and new technologies. In 2020, King Long again stepped ahead of its rivals in the automobile sector, focused on the long-term development, and grasped new opportunities; meanwhile, it took the "ice-breaking" mission and proposed the development strategy of making multi-field breakthroughs by developing a new brand, new products and new services. This pointed out the direction for brand reforms, technological breakthroughs and service upgrading based on the new vision that considers both reality and prospective changes.

Another lesson that King Long provides is that it has been a pioneer of technology application that keeps up with the times. King Long aims to become a provider of intelligent transportation solutions. With the rise of Internet of everything and new cities, construction of smart cities becomes an inevitable trend, and intelligent transportation systems are the foundation of smart cities. As a state-owned enterprise that is the participator, creator, leader and mission-taker of public transportation in China, King Long is, with its insights into the industry, moving towards the goal of growing into "a provider of solutions for smart transportation systems" who provide "safe, comfortable, environmental-friendly and convenient public transportation services".

The last lesson that King Long provides is that it adopts the most updated management and development ideas to achieve sustainable development of its brand. Based on environmental externality, the equilibrium theory, the evolution theory, the environmental strategies and value-chain management, King Long has established a rational mechanism that increases the green competition force of automobile manufacturers. This has effectively increased the competitive strength of green manufacturers in China and motivated the industry towards low-carbon development. The successful exploration and transformation of King Long reveals that only by integrating elements of all dimensions (the environment, resources, knowledge and creation, for instance) into the links of the value-chain of the automobile manufacturing industry, can we improve the value-added capacity of the value chain of automobile manufacturers and develop green competitive force. King Long has introduced to the public a new set of values from the angle of branding - RED. R stands for "Reliable": only with a reliable organization, team, partners, products and services can it win favor from the 
customers. E stands for "Efficient", which means King Long always tries to provide the right solution without a second try. D stands for "Dedicated": King Long is devoted to providing solutions for smart transportation, and with its strength in intelligent technologies and belief in craftsmanship, it always aims to create a better community for travelling. From the perspective of Jinlong bus's carbon emission standards in recent five years, diesel vehicles will implement the national five standards from 2016 to 2019,In 2020-2021, the sixth national standard will be implemented. The only difference between the fifth national standard and the sixth national standard is the carbon monoxide emission, which will decrease by $30 \%$ from $1000 \mathrm{mg} / \mathrm{km}$ to $700 \mathrm{mg} / \mathrm{km}$. After the introduction of the Sixth National Congress of the people's Republic of China, Xinneng automobile has become a general trend. Jinlong bus develops the direction of product renewal from the perspective of green manufacturing.

\subsection{GoldenHome}

GoldenHome, since its founding in 1999, specializes in manufacturing of kitchen cabinetry and has now become a leading high-end cabinet cabinetry manufacturer in China. In 2012, GoldenHome launched the "Green Home" alliance, through which it aimed to establish a new consumption mode in China based on green home and environmental protection by formulating and implementing the green standards. GoldenHome has set an example for other companies in the cabinetry manufacturing industry with its environmental development philosophy and energy-saving products. In the manufacturing of products, GoldenHome has followed the principle of ecological protection throughout the whole industry chain from selection of raw materials, to processing and production. It has paid specific attention to sheet materials and plates. In selection of raw materials, GoldenHome always meets the national standards for ecological protection and reaches Level E in Europe. It also sets up archives for its products and designs exclusive anti-fake labels. Meanwhile, it sets up a complete quality control system in production, with advanced detection devices and measures to ensure the high quality of its products, which makes GoldenHome a model company in the industry.

The success of GoldenHome in green manufacturing lies in the fact that it improves its strength by technology and seeks intelligent development. As of 2020, GoldenHome has 87 national invention patents and exterior design patents, as well as 114 practical and new technology patents. It has been a member in formulation and modification of such national s standard documents as GB/T18884.1-4 "Domestic Kitchen Equipment", and GB/T 28202-2011 "Furniture Terminology", as well as industry codes including JG/T 184-2011 "Integrated Kitchen in Residences" and "Furniture Safety Code Edge Bonding Machine". It has been recognized by Ministry of Industry and Information Technology of China as "Pilot Demonstration Enterprise for Intelligent Manufacturing", "Enterprise of Comprehensive
Standardization and New Models of Intelligent Manufacturing", "National Technological Innovation Demonstration Enterprise", and "National-level Kitchen Industrial Design Center"; it is also among the first batch of certified enterprises of industrializationinformatization integration. These honors are attributable to GoldenHome's persistence in developing its own brand since its founding and its unwavering belief that customized furniture design is an irresistible trend.

HomeGloden's success in green manufacturing also lies in its GIS information system that streamlines the links in the industrial chain and prevents wastage. The GlodenHome's GIS information system consists of six modules - data analysis system, online design system, mobile Internet application, agile supply chain platform, workshop numerical control system, data collection system. Through information technologies, it improves the management, sorts out the whole process from targeted advertising, customer management, customized kitchen cabinetry design to layout production, supply chain management to after-sales service, which helps improve the company's operation efficiency. It is hard to make breakthroughs in furniture manufacturing and production by the "workshop-style" production, and only by relying on the brand advantages can the company achieve a strong scale effect in material selection of furniture and manifest the value of the raw materials in the furniture. In 2005, GoldenHome has pursued a path of information-driven development, relying on Internet to seek further development. The company has chaired the "National 863 Plan —Large-scale Customized Manufacturing of Furniture" and completed the research project "Modularized Customization and Agile Manufacturing of Timber and Bamboo Products" in collaboration with Chinese Academy of Forestry and Nanjing Forestry University. The company has built a GoldenhHome GIS ecosystem, established a cloud solution database and online design system, and introduced the $3 \mathrm{D} \& \mathrm{VR}$ interactive experience model to give customers an immersive experience for design. With informatized infrastructure in its dual bases, GoldenHome has realized intelligent manufacturing from real-time order splitting, human-free cutting, automatic logistics, comprehensive quality control, standardized packaging, real-time delivery and simple installation.

What's also worth a mention is that GoldenHome has invested much in pooling talents and following the path of university-research-industry integration. GoldenHome has founded a smart home research institute, and it upholds the value of "co-creating ecosystem, experience-oriented services and C2B user engagement". It integrates the smart home users, product suppliers and service providers into the information interaction platform, encouraging full engagement of users in the process of customized design and production. It upgrades the smart equipment and information system, introduces data mining and artificial intelligence into industrial production, and accelerates the combination of "intelligence plus product application". 


\section{Conclusion}

One purpose of urban ecological conservation is to maintain or improve the service capacity of the urban ecological system and hence to ensure and promote sustainable development [2]. Construction of an ecologically-friendly city in Xiamen is a process in which multiple elements support each other to boost urban development, and green manufacturing is one the elements that play a crucial part within. The study cases of enterprises that have achieved great success in green manufacturing and their experience are of great importance for healthy development of green manufacturing. On that basis, a supportive guarantee system will further ensure healthy development of this industry. The municipal government of Xiamen has specified the standards for the procedures and ecological environment requirements of lighting devices: (1) no electroplating procedures are not allowed, and if there are products that need such procedures, the procedures should be completed by other companies; (2) the dust and exhaust should be collected and processed by efficient dust-removal devices before being discharged, and the processing rate should be above $95 \%$. The constraints for the electronics industry are as many as 12 regulations by regions and modules [3]. Since 2021, the proportion of new energy vehicles in the public areas of the national ecological civilization Experimental Zone and the key areas of air pollution prevention and control will not be less than $80 \%$. Formulate specific measures to bring the $\mathrm{R} \& \mathrm{D}$ investment of new energy vehicles into the assessment system of state-owned enterprises.[4] Scholars suggest that several typical industries should be selected, and the key green indicators of the industry should be determined according to the prominent problems of resources, environment, health and safety of specific manufacturing industries, so as to provide reference for other industries.[5]Green manufacturers in Xiamen have been make adjustments and adapting to the situation to address regional environmental pollution problems caused by industrial development, utilization of resources and energies, which has boosted the urban development. The main experience that Xiamen provides for developing green manufacturing brands is reflected in the following three aspects: to take macroscopic green design as the orientation and make use of resource advantages, balance urbanization with ecological conservation, optimize industrial and economic structures and improve the environment; to emphasize technological innovation and seek new solutions and methods through innovation; to strengthen tracking and survey of the industry chain, broaden the vision and take resolute actions. The experience that Xiamen provides for green manufacturing is of great referential value for coastal cities of similar situations, and is conducive to development of theories and practice of sustainable development and ecological city construction.

\section{Author information}

Zhang Xiujuan: Female, born in 1977 in Bengbu, Anhui,
China; associate professor of College of Arts \& Design of Jimei University; PhD., with research interest in art management and art industry.

\section{References}

1. 200 Jinlong buses exported to Cyprus, creating the largest export list of Chinese buses to EU and urban public transport in July 2020.

2. Chen pan., Shi Xiaoqing. (2019) Review of ecological civilization research based on literature network analysis. Acta ecologica Sinica., 39 (10): 3787-3795.

3. Xiamen Ecological Environment Bureau. (2019) Xiamen ecological environment access list. http://sthjj.xm.gov.cn/zwgk/zhengce/gfxwj/201911/t 20191125 2487856.htm.

4. New energy vehicle industry development plan (2021-2035)Chapter 8 section 2.

5. Sun Tingting, Gao Hongwei, Xi Daoyun (2021) construction of green manufacturing evaluation index system China Standardization (08): 16-20. 